\title{
FUNDAMENTALS OF BEER AND HOP CHEMISTRY
}

\section{Denis De Keukeleire}

University of Gent - Faculty of Pharmaceutical Sciences - Laboratory of Pharmacognosy and Phytochemistry - Harelbekestraat 72 B-9000 - Gent - Belgium

Recebido em 8/12/98; aceito em 23/3/99

\begin{abstract}
Beer brewing is an intricate process encompassing mixing and further elaboration of four essential raw materials, including barley malt, brewing water, hops and yeast. Particularly hops determine to a great extent typical beer qualities such as bitter taste, hoppy flavour, and foam stability. Conversely, hop-derived bitter acids account for an offending lightstruck flavour, which is formed on exposure of beer to light. These various processes are presented in detail, while due emphasis is placed on state-of-the-art hop technology, which provides brewers with efficient means to control bitterness, foam, and light-stability thereby allowing for the production of beers with consistent quality.
\end{abstract}

Keywords: beer; brewing; hops; bitter taste; flavour.

\section{INTRODUCTION}

Beer is a fermented aqueous drink based on starch and flavoured by hops. This simple definition encompasses the four essential ingredients, which are necessarily used in the brewing of beer (Scheme 1). The body of the beer is provided by barley, more specifically barley malt, and, in general, a few hundreds of grams are used for one litre of beer. The malt may be partly substituted by starch-rich adjuncts, such as rice, corn or wheat. When a slurry of barley malt and brewing water (called ' $m a s h$ ') is heated at a temperature around $60^{\circ} \mathrm{C}$, the malt enzymes, mainly amylases but also proteases, degrade starch and proteins, leading to a mixture of sugars and peptides or amino acids. For that purpose, barley must be subjected, prior to mashing, to a controlled germination, during which these enzymes are formed in the barley grain. Such germinated barley is known as barley malt. The starchto-sugar conversion is stopped by heating. Depending on the conditions (time, temperature), pale or amber-coloured or even dark malts are obtained, the colour being due to caramelization of sugars and to Maillard-type reactions. It is important to notice that the colour of beer is derived from the colour of the malt(s) used. Furthermore, it is obvious that coloured malts exhibited a distinct taste, which often is characteristic of particular dark beers.

$>$ Mashing of barley malt and starch-rich adjuncts with brewing water

$>$ Degradation of starch and proteins by malt enzymes

- Filtration -» WORT

$>$ Wort boiling - addition of whole hops

- Filtration -» HOPPED WORT

$>$ Fermentation

- Yeast removal -» "GREEN BEER" or "YOUNG BEER"

$>$ Maturation - Lagering

- Filtration -» BEER

$>$ Packaging

Scheme 1. Overview of the brewing process.

E-mail: Denis.DeKeukeleire@rug.ac.be
After filtration, the sugar solution, in brewers' jargon called 'wort', is transferred to the brewing kettle, where it is boiled during at least one hour with the addition of hops (Humulus lupulus L.). The amount of hops needed is only a fraction of the substantial quantities of malt used in the brewery. Usually, a few grams of hops are sufficient as a quantitatively minor, but qualitatively major ingredient with crucial impact on welldefined beer features. Besides the formation of insoluble complexes with proteins and polypeptides, contributing to the colloidal stability of beer, hops sterilize the wort solution, which takes care of the bacteriological stability of beer. The most important asset of hops is the bitter taste conferred to, particularly, blond beers. Furthermore, hops are necessary for the stabilization of beer foam, while, on the other hand, the most precarious off-flavour in beer, called lightstruck flavour, involves degradation of hop-derived components (see below).

After cooling and removal of spent hops, the liquid, known as 'hopped wort' is pumped to the fermentation vessels and yeast is added under aeration for growth. During the anaerobic phase yeast cells convert sugars to ethanol and carbon dioxide. Depending on the temperature during fermentation and the nature of yeast collection at the end of the fermentation period, beers are distinguished as being produced by 'bottom fermentation' or 'top fermentation'. Yeast strains, appropriate for bottom-fermented beers (Saccharomyces carlsbergensis), are active below $5^{\circ} \mathrm{C}$ and they settle to the bottom of the fermentor after production of about 5\% ethanol. Conversely, yeasts, typical for the production of top-fermented beers (Saccharomyces cerevisiae), operate at ambient temperature and resist higher concentrations of ethanol, up to $12 \%$. When the activity stops, the yeast cells collect to the top as a dense foam.

A typical fermentation takes about one week thereby delivering a so-called 'green beer' or 'young beer', which is not drinkable, as a number of offending (bad taste and smell) compounds are formed during fermentation. Consequently, beers need a maturation or lagering period of several weeks at about $0^{\circ} \mathrm{C}$, during which the unwanted components are slowly decomposed. High concentrations of diacetyl and pentane-2,3-dione are particularly obnoxious for the quality of lager beers ('pilsner-type') and scrutinous monitoring is required. Only after the content has decreased below critical values (ppb-ranges), beer can be packaged. For prolonged conservation beers may be pasteurized. Special beers often require a slow (several months) second fermentation, usually in oak kegs, to generate sour flavours. 


\section{COMPLEX HOP FLAVOUR CHEMISTRY}

The tastes of varying beer types are derived from a judicious choice of raw materials. Hops, in particular, account, in addition to the bitter taste, for a delicate hoppy flavour in beer. Until now, this extremely valuable organoleptic feature has not been fully defined. It is generally accepted that the hoppy aroma in beer is a complex of sensory impressions resulting from many different volatile compounds at low concentrations, many of them acting in synergism ${ }^{1}$. It appears that volatiles, contained in the hop oil (0.5-3\% in hops), and non-volatiles, present in the hop polyphenolic fraction (3-6\%), contribute to a full mouthfeel during beer tasting. However, the composition of these hop fractions is very complex and their study has been hampered by the low and varying concentrations normally found in beer. Thus, detailed insights are, at present, elusive.

Obviously, during the boiling of hops in wort many constituents are volatilized or oxidized and the hop-derived constituents, present in beer, are to a large extent different from the original molecules, present in hops. It should be interesting to trace the fate of individual volatile hop constituents, particularly terpenes, such as myrcene, caryophyllene, humulene and farnesene, during wort boiling, but the variability due to differing conditions and beers preclude that general statements be made. An inevitable conclusion is that the very intricate composition of the hop oils becomes even more complex during wort boiling.

Many brewers try to conserve part of the original composition by adding precious hop varieties ('aroma hops') near the end of the boiling period. This procedure, known as 'late hopping', may be combined with 'dry hopping', a special technique involving addition of hops to beer just before packaging. By doing so, some original hop constituents are directly transferred to the aqueous matrix thereby imparting a discrete hoppy character to the beer. The growing success of small brewers (microbreweries, brewpubs) suggests increasing recognition of the opportunities that the use of hops presents, in particular for developing various hop aromas and flavours.

Hops may contribute up to about one third of the total polyphenols in beer. Little doubt now remains that, amongst the polyphenolics, the low-molecular-weight proanthocyanidins determine the colloidal stability of beer. The net result of boiling is a dramatic change in the already complex polyphenol composition of wort $^{2}$. It seems to be impossible to get a reasonable insight into the fate of the polyphenolic mixture. Part of the complexity can undoubtedly be ascribed to the ready oxidation and the ease of polymerization of many polyphenols.

Hop polyphenols are found as monomers, dimers, trimers, but also as more complex forms associated with nitrogenous components. It is common practice to distinguish between 'chill haze' and 'permanent haze'. The polyphenols combine slowly with proteins to form chill haze when cooled, but which redissolves when warmed up. As the polyphenols polymerize and grow larger, they become insoluble at room temperature to form irreversible haze. The extent to which a beer requires stabilization depends on its shelf-life and the storage conditions after packaging. It appears that hop polyphenols are a group of substances with interesting effects on taste and taste stability of beers. Taking, moreover, the pronounced 'natural' antioxidant character of particular polyphenols into account, it is obvious that, in the future, more attention will be focussed on the various roles of polyphenols in brewing.

\section{THE CHEMISTRY OF THE BITTER BEER TASTE}

Bitter profiles in beer are well understood, as only few precursors are present in hops, thereby facilitating research of beer bitter components ${ }^{3,4}$. Perhaps the most important class of hop compounds are the hop acids, which are distinguished as

alpha-acids or humulones (1) and beta-acids or lupulones (2) (Scheme 2). The two series comprise, in fact, three constituents differing in the nature of the side chain, which is derived from the hydrophobic amino acids, leucine, valine and isoleucine, for humulone (1a)/lupulone (2a), cohumulone (1b)/colupulone (2b) and adhumulone (1c)/adlupulone (2c), respectively. An intriguing feature of the hop acids is their exceptionally high content, up to $25 \%$ or even more, of the dry weight of the hop cones. The relative proportions of the individual constituents depend strongly on the hop variety and, for a given variety, on the conditions of growing. The hop acids occur as paleyellowish solids in the pure state, are weak acids, exhibit very poor solubility in water and have almost no bitter taste.

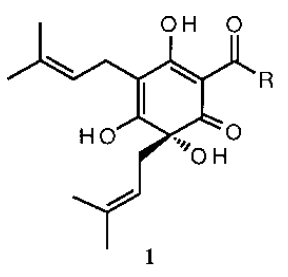

ALPHA-ACIDS

HUMULONE (1a) COHUMULONE (1b) ADHUMULONE (1c)

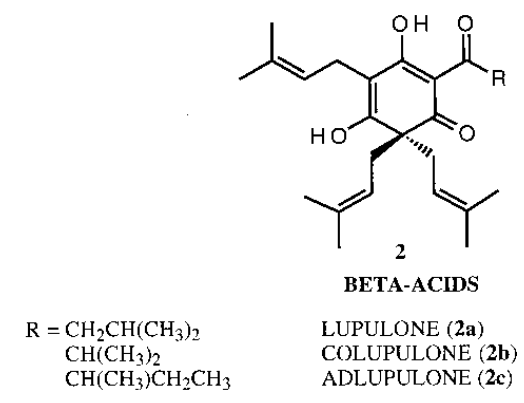

Scheme 2. Structures of humulones and lupulones.

The hop acids have pronounced bacteriostatic activity; they strongly inhibit the growth of Gram-positive bacteria. This action has been attributed to the interference of the prenyl group, characteristic of the side chains of the hop acids, with the function of the cell plasma membrane. It appears that the more prenyl groups (three in the beta-acids) are present, the stronger the bacteriostatic action is. This remarkable bioactivity is of importance for killing micro-organisms during wort boiling, which ultimately leads to a sterile beer.

Varying applications have been explored to exploit the bacteriostatic activity of the beta-acids. A highly interesting use is in the sugar industry to control and reduce bacterial activity during extraction of sugar beets ${ }^{5}$. By dosing the hop beta-acids periodically in amounts of $10 \mathrm{~g}$ per ton of beet, the lactic acid content of raw juice was reduced to $400 \mathrm{ppm}$ without influence on the fermentation. Investigations on the fate of the hop compounds showed that residual values in sugar, molasses and pulp are undetectable or uncritical. It appears that formalin, a widespread processing aid in the sugar industry, could be advantageously replaced by hop beta-acids.

Otherwise, the beta-acids are very sensitive to oxidative decomposition and most oxidation reaction products possess unpleasant organoleptic characteristics. Notwithstanding the fact that the beta-acids may possibly protect beer against oxidation, they are, in general, considered a negative factor in brewing and a number of brewers select hop varieties, that are poor in beta-acids.

The major component of the mixture of alpha-acids is humulone (1a). While the relative amounts of humulone (1a) and cohumulone (1b) are variety-dependent (20-50\%), adhumulone (1c) constitutes invariably ca. $15 \%$ of the mixture. Cohumulone has been associated with a poor hop quality, although this issue is not proven unambiguously ${ }^{6}$. Detailed analysis by HPLC (high performance liquid chromatography) MS (mass spectroscopy) reveals the presence of other related alpha-acids, albeit in very small concentrations.

The transformations of the humulones during wort boiling have been studied in great detail ${ }^{3}$. By far the most important chemical conversion overall during the brewing of beer is the thermal isomerization of the alpha-acids or humulones $(\mathbf{1})$ to the iso-alpha-acids or isohumulones $(\mathbf{3}+\mathbf{4})$ via an acyloin-type ring 
contraction (Scheme 3). Each humulone gives rise to two epimeric isohumulones, which are distinguished as cis-isohumulones (3) and trans-isohumulones (4), depending on the spatial arrangement of the tertiary alcohol function at $\mathrm{C}(4)$ and the prenyl side chain at $\mathrm{C}(5)$. The terms trans and cis indicate that these groups point to opposite faces and to the same face of the five-membered ring, respectively.

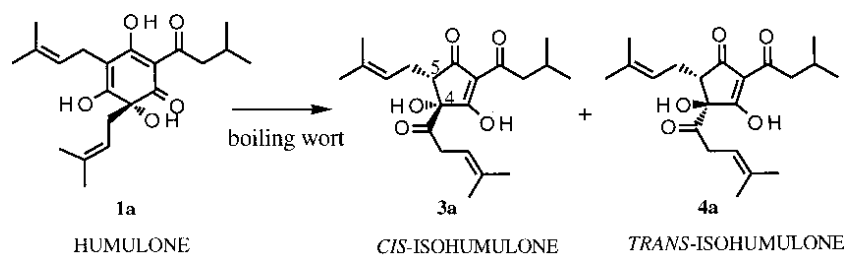

Scheme 3. Conversion of the humulones to the isohumulones.

Thus, humulone (1a) is isomerized to cis-isohumulone (3a) and trans-isohumulone (4a). Consequently, six major iso-alphaacids ( $c$ is-isohumulone and trans-isohumulone, $c i s$-isocohumulone and trans-isocohumulone, cis-isoadhumulone and transisoadhumulone) are present in beer resulting from the conversion of the three major alpha-acids, humulone, cohumulone and adhumulone, respectively. Figure 1 represents a reversed-phase HPLC separation of the six major isohumulones in a typical lager beer. The early part of the chromatogram refers to an oxidized fraction and is representative of the 'freshness' of the iso-alpha-acids.

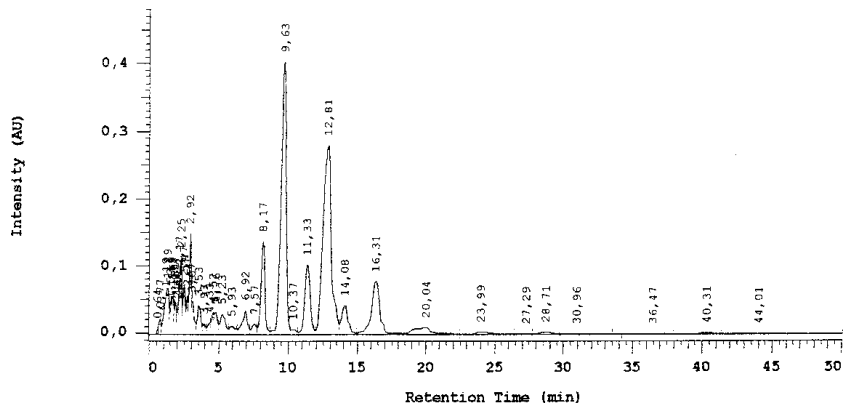

Figure 1. HPLC separation of the isohumulones in a lager beer. (respective retention times: trans-isocohumulone (4b): $8.1 \mathrm{~min}$; cisisocohumulone (3b): $9.5 \mathrm{~min}$; trans-isohumulone (4a): $11.5 \mathrm{~min}$; cisisohumolone (3a): $12.5 \mathrm{~min}$; trans-isoadhumolone (4c): $14.2 \mathrm{~min}$; cisisoadhumolone (3c): $16.3 \mathrm{~min}$ )

The ratio of the isohumulones depends on the reaction conditions. In the wort medium it is normally 68:32 in favour of the cis-compounds. However, the cis-compounds are much more stable (half-life $>5$ years) than the trans-isomers (halflife of ca. 1 year) during the course of time. This affects, obviously, the cis:trans ratio and has significant consequences with respect to taste and flavour stability. Thus, it appears interesting to have the highest content of cis-isohumulones possible in the mixture of isohumulones.

The iso-alpha-acids are intensely bitter, almost equivalent to quinine, the reference compound for comparisons of bitterness. The threshold value in water has been estimated at $6 \mathrm{ppm}$. The iso-alpha-acids constitute the quantitatively most important fraction of hops in beer and they account for the typical bitter beer taste. Their concentrations vary widely, from $15 \mathrm{ppm}$ in typical American lager beers to nearly 100 ppm in very bitter English ales. The real taste, as perceived by beer consumers, is largely modified by complexation with residual sugars, present in beers, and, thus, the bitterness is evaluated as 'pleasant bitterness'.
There are conflicting views on the bittering power of the individual isohumulones, mainly as a consequence of differences in purity of the compounds that have been used in taste trials. Purification of iso-alpha-acids is particularly difficult and reported results should be interpreted with great caution. The utilization of cohumulone (1b) is better than that of the other alpha-acids due to the more polar character and the increased solubility in water. The organoleptic features of the isocohumulones, however, are subject to some suspicion, as they generate a more 'harsh' bitterness with respect to the other isohumulones.

In addition to imparting bitter taste to beer, the iso-alphaacids exhibit other interesting features: they have tensioactive properties, thereby stabilizing the beer foam, and inhibit the growth of Gram-positive bacteria, thus protecting beer against these micro-organisms. On the other hand, lactic acid bacteria in beer are resistant to iso-alpha-acids.

\section{THE LIGHTSTRUCK FLAVOUR OF BEER}

It has been thought that iso-alpha-acids and phenolic compounds are key components with regard to beer stability. Iso-alpha-acids are partly responsible for production of ageing off-flavours, including stale and cardboard flavours ${ }^{7}$. Volatile aldehydes, such as trans-non-2-enal, are formed during storage of bottled beer from various precursors, including hop lipids. On the other hand, it has been known for quite some time that beer decomposes on exposure to light, thereby generating an offending 'skunky' flavour. Thus, beer must be stored, either in opaque cans, or in green or brown bottles, in order to prevent light from being transmitted through the glass.

The cause for this phenomenon is the vulnerability of the iso-alpha-acids to light. The resulting decomposition leads to formation of the so-called 'lightstruck flavour'. The lightsensitive chromophore in the isohumulones is the acyloin group composed of the tertiary alcohol function at $\mathrm{C}(4)$ and the carbonyl group of the side chain at C(4). Activation of, for example, the isohumulones 3a and 4a with UV light causes bond cleavage by a Norrish Type I reaction, leading to a ketylacyl radical pair. Subsequent loss of carbon monoxide from the acyl radical and recombination of the resulting fragment with a thiol radical furnish 3-methylbut-2-ene-1-thiol, also known as 'skunky thiol' (5, Scheme 4), together with dehydrohumulinic acid $(\mathbf{6 a})^{8}$.
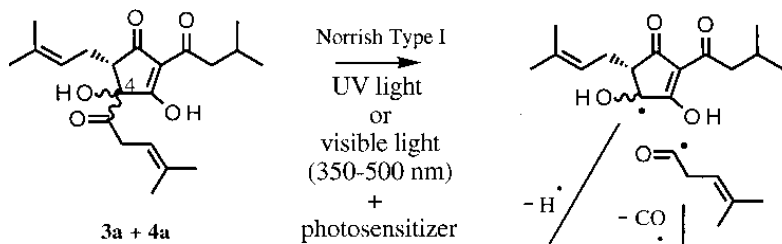

$3 \mathbf{a}+\mathbf{4 a}$

photosensitizer
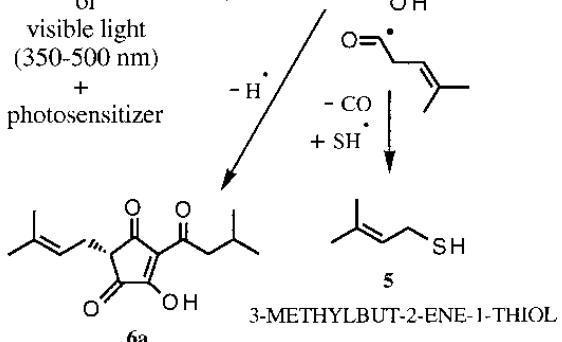

$6 a$

Scheme 4. Formation of the lightstruck flavour in beer.

The mechanism for the formation of the lightstruck flavour was confirmed by the unambiguous identification of 3methylbut-2-ene-1-thiol in illuminated beers. The flavour threshold of the thiol is so low that even concentrations of few ppb spoil irreversibly the beer quality. The thiol is formed also on exposure to visible light or sunlight. Since the iso-alphaacids do not absorb in the visible region, the reaction is photosensitized, in first instance by riboflavin (vitamin $\left.\mathrm{B}_{2}\right)^{9}$. 


\section{NOVEL HOP TECHNOLOGY TO CONTROL BITTERNESS, FOAM AND LIGHT-STABILITY OF BEERS}

The isomerization of alpha-acids to iso-alpha-acids during wort boiling suffers from low yields, which are seldom higher than $30 \%$. The transfer of the alpha-acids from the vegetative hop material, the restricted solubility of the alpha-acids in the aqueous matrix and the almost neutral wort ( $\mathrm{pH}$ 5-5.5) are critical factors. A better utilization of hops is effected when hop extracts are used (40-50\%). Liquid or supercritical carbon dioxide is, indeed, an excellent medium to extract both the hop acids and the hop oil from hops. Thus, new technologies aimed at exploiting the full potential of hops and optimizing the utilization of hops in the brewing of beer - on the basis of original findings in our laboratory - are gaining considerable importance. Opportunities for the development of more flavour-consistent beers and diversified beer types abound.

Hops are fractionated on an industrial scale to a variety of 'hop products', based on liquid or supercritical carbon dioxide extracts ${ }^{4}$. While the polyphenols reside in the spent hops, an extract, rich in hop acids, or an extract, rich in hop oil, may be obtained, depending on the operating temperatures and pressures. The hop volatiles can be separated from the oil-rich extract as 'hop essences'. Crude fractionation of the total hop oil provides a 'floral oil' and a 'spicy oil', respectively. The hop alpha-acids are accessible from a hop-acids-rich extract using selective, $\mathrm{pH}$ controlled solvent extraction. The alpha-acids prevail then as a concentrate, which can readily be isomerized to the iso-alphaacids, the principal beer bitter constituents. Isomerization may be carried out by heating solid salts of particular metal ions, e.g. magnesium(II) humulates. Alternatively, irradiation of the alphaacids in the wavelength region of 350-366 nm (UV-A light) provokes a fully regio- and stereoselective photorearrangement, thereby affording exclusively trans-isohumulones $(\mathbf{4})^{8}$. Yields are in both cases almost quantitative.

These isohumulones, thus produced off-line (i.e. not by brewers, but by hop processors), are formulated as potassium salts in concentrated aqueous solution. Such advanced hop products can be applied to add bitterness to beer or to adjust bitterness levels at any stage during the brewing process. Best organoleptic results are obtained when the isohumulones are added near the end of wort boiling, hence when they fully participate in fermentation and lagering. It was found that introduction of isohumulones just before packaging must be accompanied by addition of very small amounts of hop oil (ca. $1 \mathrm{ppm}$ ) in order to make such 'advanced' beers indistinguishable from 'traditional' beers ${ }^{10}$. Yields of isohumulones, thus applied, exceed $80 \%$.

Further manipulation of the iso-alpha-acids is carried out with the principal aim to brew foam- and light-stable beers. In practice, iso-alpha-acids are converted to reduced iso-alphaacids with quite interesting properties ${ }^{11}$. Three major types of reduced iso-alpha-acids should be considered depending on the number of hydrogen atoms (dihydro, tetrahydro, hexahydro) incorporated during reduction.

Sodium borohydride reduction of the carbonyl group in the side chain at $\mathrm{C}(4)$ of the isohumulones gives rise to dihydroisohumulones (also known as 'rho-isohumulones'), which are perfectly light-stable, as the light-sensitive acyloin group has been converted to a diol. Since formation of the secondary alcohol function is accompanied by creation of a new chiral centre, two epimeric dihydro-iso-alpha-acids arise from each isoalpha-acid, e.g. compounds $7 \mathbf{a}$ and $\mathbf{8 a}$ from trans-isohumulone (4a) (Scheme 5). Consequently, a mixture of twelve dihydroiso-alpha-acids may result from reduction of the six major isoalpha-acids. However, dihydro-iso-alpha-acids products are usually less complex due to the reaction conditions employed and the resulting selectivities. Substitution of iso-alpha-acids by dihydro-iso-alpha-acids allows brewing of light-stable beers, which can be bottled in clear glass.

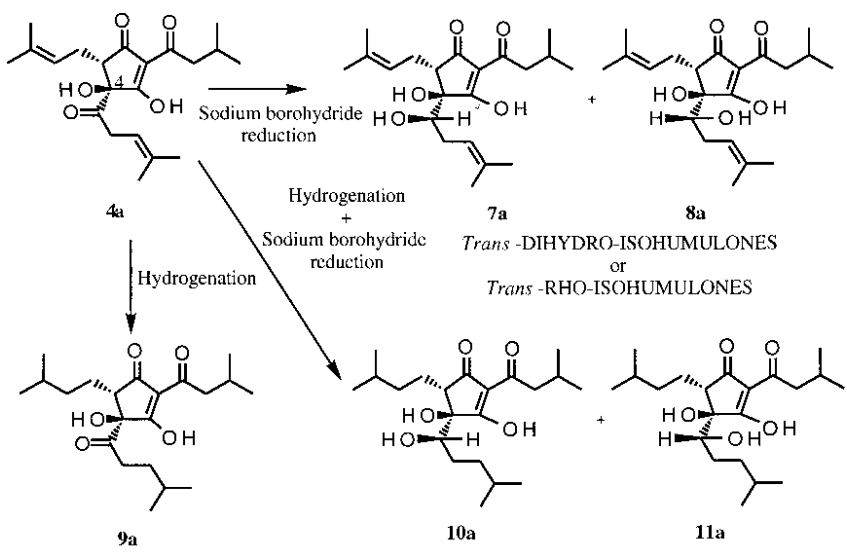

Trans-TETRAHYDRO-ISOHUMULONE Trans-HEXAHYDRO-ISOHUMULONES

Scheme 5. Production of reduced isohumulones.

Tetrahydro-iso-alpha-acids are obtained by hydrogenation of the double bonds in the side chains of the iso-alpha-acids, e. g. trans-tetrahydro-isohumulone $(\mathbf{9 a})$ from trans-isohumulone (4a). Commercially available tetrahydro-iso-alpha-acids are produced as a mixture of six tetrahydro-iso-alpha-acids. Via reversed phase HPLC analysis of a beer, made from iso-alpha-acids, in conjunction with tetrahydro-iso-alpha-acids, the composition of the bitter constituents can be revealed, as shown in Figure 2. Saturation of the double bonds leads to diminished reactivity and enhanced hydrophobicity, which has a pronounced foampositive effect. Since the acyloin group is still present, photochemical reactions may occur on light exposure, although the allyl radical, intervening in the formation of 3-methylbut-2-ene1-thiol (5), can no longer be formed. Hop products, based on tetrahydro-iso-alpha-acids, have become very popular recently, particularly in view of the pronounced propensity to stabilize beer foam (Scheme 6). Brewers take advantage of this by adding few ppm of tetrahydro-iso-alpha-acids to create a creamy head on a glass of beer.

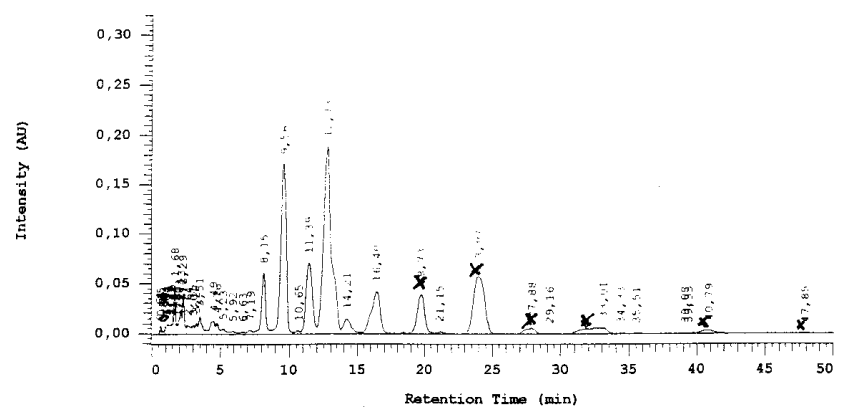

Figure 2. HPLC analysis of a beer brewed using isohumulones and tetrahydro-isohumulones. (elution order of isohumulones: as in Figure 1.; tetrahydro-isohumolones marked, respective retention times: transtetrahydro-isocohumolones: $19.7 \mathrm{~min}$; cis-tetrahydro-isocohumulone: 24.0 min: trans-tetrahydro-isohumolone $(9 a)$ : 27.9 min: cis-tetrahydroisohumolone: $32.5 \mathrm{~min}$; trans-tetrahydro-isoadhumolone: $40.8 \mathrm{~min}$; cistetrahydro-isoadhumolone: $47.9 \mathrm{~min}$ ).

Hexahydro-iso-alpha-acids are accessible by a combination of the aforementioned processes, i.e. reduction of the sidechain carbonyl group and hydrogenation of the double bonds in the iso-alpha-acids. Trans-isohumulone (4a) would afford trans-hexahydro-isohumulones $\mathbf{1 0 a}$ and 11a, while the mixture of hexahydro-iso-alpha-acids could theoretically be composed 


\section{COMPOUNDS}

Isohumulones

Dihydro-isohumulones (rho)

Tetrahydro-isohumulones

Hexahydro-isohumulones

Scheme 6. Comparision of isohumulones and reduced isohumulones regarding bitterness and foam.

of twelve isomers and homologues. Real samples of hop products based on hexahydro-isohumulones are much simpler as observed on HPLC separation.

\section{CONCLUSIONS}

Beer is an extremely complex drink and several hundreds of constituents have been identified hitherto. Hops are vital to the organoleptic qualities of beer, including taste and flavour. During the multi-stage brewing process many hop components are modified, but even the use of sophisticated separation and analysis techniques has, until now, not allowed to identify unambiguous relations between particular hop-derived compounds and sensory characteristics.

As opposed to the intricate chemistry of hop oils and hop polyphenols, the bitter taste features of beer have been adequately profiled. Alpha-acids or humulones are converted during wort boiling to iso-alpha-acids or isohumulones, which impart the typical bitter taste to beer. Modern hop technology has unlocked the full potential of hops by providing novel hop products, which allow brewers to adjust desired beer properties. Moreover, off-flavours, such as the lightstruck flavour, can be obviated by bittering beers with advanced hop products, based on reduced iso-alpha-acids or reduced isohumulones, thereby rendering beers light-stable.

Both bottom- and top-fermented beers, using advanced hop products, have been made in our pilot brewing facilities and sensory analysis proved their superior quality with respect to more traditional brews. Judicious application of advanced analytical methods has been essential to the successful penetration of new hop technologies into the beer world. State-of-theart analyses involving high-efficient chromatographic variants (e.g. reversed phase HPLC) ${ }^{12}$ and electro-driven separation methods (e.g. CZE) ${ }^{13}$ have superseded classical unspecific protocols. Validated quantification of various hop-derived compounds must support beer quality control from a modern brewing perspective.

\section{REFERENCES}

1. Moir, M.; Hop Aromatic Compounds. In European Brewery Convention Monograph XXII - EBC-Symposium on Hops, Zoeterwoude, The Netherlands, May/June 1994, Verlag Hans Carl, Nuremberg, Germany, 1994, pp. 165-180.

2. Forster, A.; Beck, B; Schmidt, R.; Untersuchungen zu Hopfenpolyphenolen. In European Brewery Convention, Proc. 25th Congr., Brussels, 1995, Oxford University Press, Oxford, England, 1995, pp. 143-150.

3. Verzele, M.; De Keukeleire, D.; Chemistry and Analysis of Hop and Beer Bitter Acids, Elsevier, Amsterdam, The Netherlands, 1991.

4. Benitez, J. L.; Forster, A.; De Keukeleire, D.; Moir, M. Sharpe, F. R.; Verhagen, L. C.; Westwood, K. T.; Hops and Hop Products, Verlag Hans Carl, Nuremberg, Germany, 1997.

5. Pollach, G.; Hein, W.; Hollaus, F.; Zuckerind. 1996, 121, 919 - Hein, W.; Pollach, G.; Zuckerind. 1997, 122, 940.

6. Meilgaard, M.; J. Inst. Brew. 1960, 66, 35.

7. Kamimura, M.; Kaneda, H.; Off-flavors in Beer. In Offflavors in Foods and Beverages, Ed. Charalambous, G., Elsevier, Amsterdam, The Netherlands, 1992, pp. 433-472.

8. De Keukeleire, D.; Blondeel, G. M. A.; Tetrahedron Lett. 1979, 1343.

9. De Keukeleire, D.; Heyerick A.; University of Gent, unpublished results, 1998.

10. De Cooman, L.; Overmeire, H.; Aerts, G.; De Keukeleire, D.; University of Gent, 1998, unpublished results.

11. Goldstein, H.; Ting, P.; Post Kettle Bittering Compounds: Analysis, Taste, Foam and Light Stability. In European Brewery Convention Monograph XXII - EBCSymposium on Hops, Zoeterwoude, The Netherlands, May/June 1994, Verlag Hans Carl, Nuremberg, Germany, 1994, pp. 154-162.

12. De Cooman, L.; Everaert, E.; De Keukeleire, D.; Phytochem. Anal. 1998, 8, 1.

13. De Keukeleire, D.; David, F.; Haghebaert, K.; Sandra, P.; J. Inst. Brew. 1998, 104, 75. 